\title{
Thermal Wake Studies During the August 21 2017 Total Solar Eclipse
}

\author{
Kaye Smith, ${ }^{1}$ and Erick Agrimson ${ }^{2}$ \\ St. Catherine University, St. Paul, Minnesota, 55105 \\ Brittany Craig ${ }^{3}$ \\ General Dynamics, Bloomington, Minnesota, 55341
}

Alynie Xiong, Grace Maki, Peace Sinyigaya, Vina Onyango-Robshaw, Ana Taylor, Rachel Lang ${ }^{4}$

St. Catherine University, St. Paul, Minnesota, 55105

Rachel DuBose ${ }^{5}$

SkyWater Technology Foundry, Bloomington, Minnesota, 55425

Gordon McIntosh ${ }^{6}$

University of Minnesota - Morris, Morris, Minnesota, 56267

and

James Flaten ${ }^{7}$

MN Space Grant/University of Minnesota -Twin Cities, Minneapolis, Minnesota, 55455

\begin{abstract}
A thermal wake occurs when a high altitude balloon (HAB) influences and changes the surrounding ambient atmospheric temperature of the air through which it passes. This effect warms the air below the balloon to greater than the ambient temperatures during daytime flights, and cooler than ambient temperatures during nighttime flights. The total solar eclipse of August $21^{\text {st }}$, 2017, provided us with an opportunity to study these balloon-induced temperature effects under the unique conditions of neither full daytime nor full nighttime. To measure these temperature effects, St. Catherine University and the University of Minnesota, Morris, flew over 40 temperature sensors suspended beneath weather balloons ascending within the path of totality. Stratospheric temperature data collected during the eclipse show a thermal wake profile that is neither daytime nor nighttime; an eclipse thermal wake.
\end{abstract}

\footnotetext{
${ }^{1}$ Assistant Professor of Physics, St. Catherine University, 2004 Randolph Ave., St. Paul, MN 55105.

${ }^{2}$ Associate Professor of Physics, St. Catherine University, 2004 Randolph Ave., St. Paul, MN 55105.

${ }^{3}$ St. Catherine Alumna, Systems Engineer, General Dynamics, 8800 Queen Ave. S., Bloomington, MN, 55341.

${ }^{4}$ Undergraduate Student, St. Catherine University, 2004 Randolph Ave., St. Paul, MN, 55105.

5 St. Catherine Alumna, Process Technician Specialist, SkyWater Technology Foundry, 2401 E $86^{\text {th }}$ St., Bloomington, MN 55425.

${ }^{6}$ Professor of Physics, University of Minnesota, Morris, 600 East $4^{\text {th }}$ St.., Morris, MN, 56267.

${ }^{7}$ Associate Director of the MN Space Grant Consortium, Aerospace Engineering and Mechanics Department, University of Minnesota - Twin Cities, 110 Union St., SE, Minneapolis, MN, 55455
} 


\section{Nomenclature}

$\begin{array}{ll}H A B & =\text { High Altitude Balloon } \\ P & =\text { Air Pressure } \\ D & =\text { Day flight } \\ N & =\text { Night flight } \\ E & =\text { Eclipse flight } \\ \text { Wake boom } & =\text { device with attached temperature sensors, suspended beneath a weather balloon } \\ \mathrm{d} & =\text { heat exchange layer thickness } \\ \text { Re } & =\text { Reynolds Number }\end{array}$

\section{Introduction}

The total solar eclipse of August 21 ${ }^{\text {st }}, 2017$, (Fig. 1) provided researchers with an opportunity to investigate atmospheric based changes within the Moon's shadow. Throughout a solar eclipse this shadow provides a moving region where heating from the Sun's radiation is reduced, creating a predictable perturbation for studying the atmosphere's response to changes in solar heating. Eckerman [1] theoretically modeled an eclipse and Ramkumar [2] experimentally measured temperature changes using radiosondes during a solar eclipse. Their results suggest that the stratosphere cools due to radiation heating losses during solar obscuration. As Harrison and Marlton $[3,4]$ suggest, "the solar radiation reduction shall be a proportion of the sun obscured for a particular location and time of year."

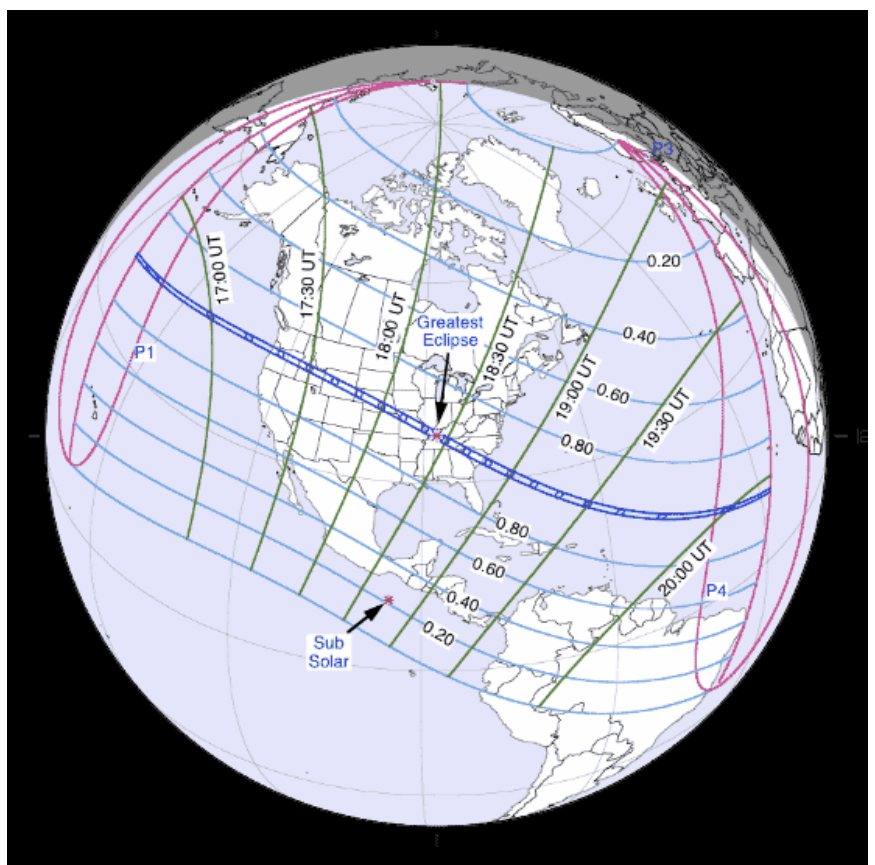

Fig. 1. Eclipse totality path in blue.

https:/eclipse.gsfc.nasa.gov/SEmono/TSE2017/TSE2017fig/TSE2017-1.gif

Building upon previous work [5-9] measuring how the proximity of an ascending HAB affects atmospheric temperature measurements beneath the balloon, we studied thermal effects and transitions in the stratosphere during the solar eclipse. Based on references [1-4], we hypothesized that radiation cooling in the path of the eclipse would affect temperature measurements, especially those made in the stratosphere. We further predicted that daytime thermal wake profiles measured under HABs would become like nighttime thermal wake profiles as a result of eclipse-induced solar radiation reduction. 


\section{Overview of the thermal wake}

Both "balloon" [10] and "thermal" [11-13] wakes exist beneath an ascending HAB. The width and mixing of the balloon wake depends on the ascent Re as well as on the balloon's shape and surface roughness. The width and mixing of the thermal wake depends on the ascent rate of the balloon, the type of lift gas used in the balloon, and the required amount of heat [12]. During a daytime flight the air directly beneath the balloon will be warmer than the ambient air due to solar radiation hitting the balloon $[12,14]$. During night flights the adiabatic expansion and cooling of the lift gas inside the balloon dominates, lowering the balloon skin temperature and producing a thermal wake that is uniformly cooler than the ambient air. Fig. 2 [12], modified here, suggests an asymmetry in the thermal wake during daylight flights when the sun-side of the balloon receives more thermal energy than the anti-sun (shade) side, resulting in a thermal wake that is warmer on the sun-side and cooler on the anti-sun side, but still warmer than the ambient air temperature. For radiosondes Barat [10] states and Jumper [15] agrees that payload distance below the balloon (L) divided by the balloon diameter (D) must be greater than 20 to minimize thermal wake contamination of temperature measurements. To be "in the thermal wake" we make temperature measurements $6 \mathrm{~m}$ below the balloon where $\mathrm{L} / \mathrm{D}$ is never greater than 2.00 (see Table 1.)

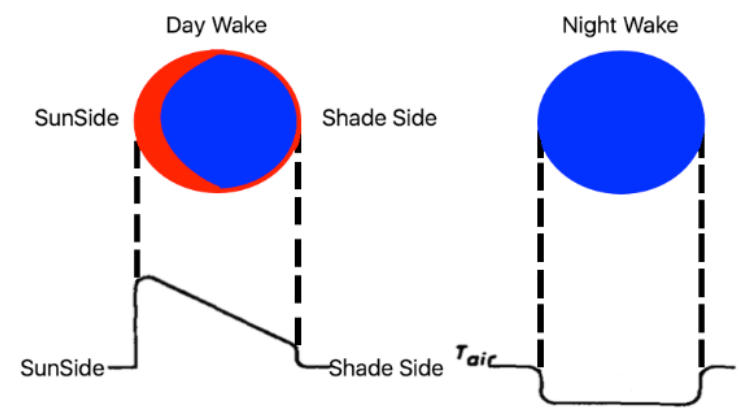

Fig. 2: Asymmetrical and symmetrical temperature wake profiles beneath ascending balloons during day and night ascents. Adiabatic cooling of the lifting gas is always present but solar warming during the day dominates. Figure modified from Tiefenau [12].

\begin{tabular}{|c|c|c|c|c|c|c|}
\hline $\begin{array}{c}\text { Altitude } \\
(\mathrm{km})\end{array}$ & $\begin{array}{c}\text { Air } \\
\text { Pressure }(\mathrm{hPa})\end{array}$ & $\begin{array}{c}\text { Balloon } \\
\text { Volume }\left(\mathrm{m}^{3}\right)\end{array}$ & $\begin{array}{c}\text { Balloon } \\
\text { Diameter }(\mathrm{m})\end{array}$ & $\begin{array}{c}\text { Balloon } \\
\text { Cross section } \\
\left(\mathrm{m}^{2}\right)\end{array}$ & $\begin{array}{c}\text { Reynold's } \\
\text { Number Re }\end{array}$ & $\begin{array}{c}\text { Payload } \\
\text { Location } \\
\text { Ratio L/D }\end{array}$ \\
\hline 0 & 1013.25 & 14.13 & 2.98 & 7.06 & $1.22 \mathrm{E}+06$ & 2.00 \\
\hline 5 & 540.19 & 23.52 & 3.54 & 9.92 & $9.54 \mathrm{E}+05$ & 1.68 \\
\hline 10 & 264.36 & 41.95 & 4.30 & 14.59 & $7.27 \mathrm{E}+05$ & 1.39 \\
\hline 15 & 120.44 & 89.40 & 5.54 & 24.16 & $4.50 \mathrm{E}+05$ & 1.08 \\
\hline 20 & 54.74 & 196.66 & 7.20 & 40.87 & $2.66 \mathrm{E}+05$ & 0.832 \\
\hline 25 & 25.11 & 438.54 & 9.42 & 69.76 & $1.53 \mathrm{E}+05$ & 0.637 \\
\hline 30 & 11.71 & 960.22 & 12.22 & 117.62 & $8.89 \mathrm{E}+04$ & 0.490 \\
\hline 35 & 5.58 & 2102.69 & 15.88 & 198.34 & $5.07 \mathrm{E}+04$ & 0.378 \\
\hline
\end{tabular}

Table 1: Balloon dimensions, Re and L/D ratio based on standard atmospheric conditions [16], $1.5 \mathrm{hPa}$ overpressure and a $6 \mathrm{~m} / \mathrm{s}$ ascent rate.

Fig. 3 shows calculated cross sectional areas of both the balloon and the thermal wakes during a HAB ascent using standard atmospheric conditions [16] and the methods of Tiefenau [12] (see Table 2.) Balloon size measured using an upward-pointing video camera is shown for comparison. Starting balloon volume was calculated based on 1.5 T-size helium tanks; the amount of lifting gas required for our stack weight. These results for the area of the 
thermal wake are based on a spherical balloon shape and assume the balloon is in transition between laminar and turbulent flow meaning it is not possible to predict the exact area of the thermal wake but results agree with Jumper's claim [15], "that the mass of the thermal wake is only a small fraction of the mass of the velocity disturbance (balloon wake) discussed by Barat" [10].

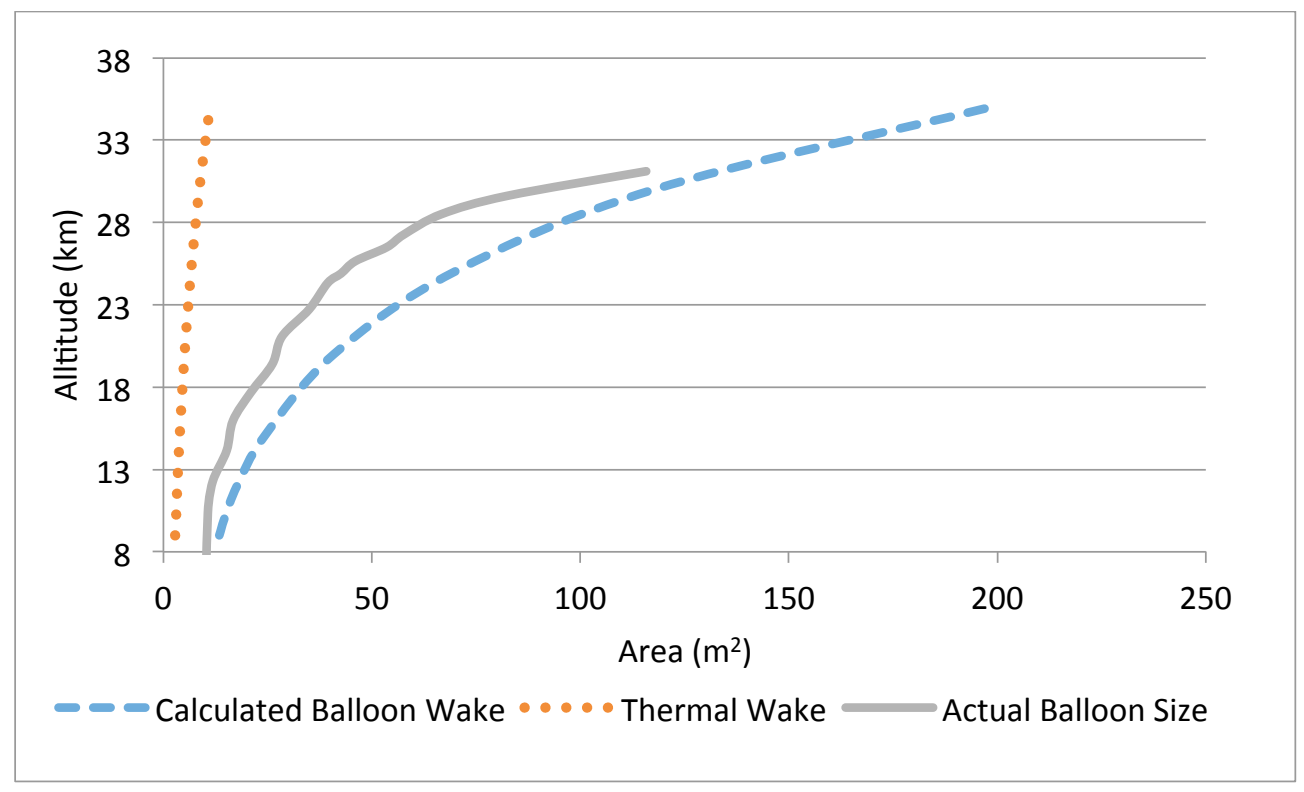

Fig. 3: Balloon wake and the thermal wake cross sectional areas plotted against altitude for an ascending HAB. Calculations are based on standard atmospheric conditions [16] using a $1600 \mathrm{~g}$ balloon with Helium as the lifting gas. Actual balloon size was estimated using video footage from an upward-pointing camera flown during an eclipse flight.

We make our temperature measurements using a device called a wake boom (pictured in Fig.4): a carbon fiber rod with temperature sensors spaced along the $3.5 \mathrm{~m}$ boom length giving a maximum end to end sensor spacing of $3.2 \mathrm{~m}$. Our sensors are mounted above the carbon fiber rod, pointing upward to avoid thermal contamination by the rod itself as discussed by Eaton [17] and Kyrazis [18].

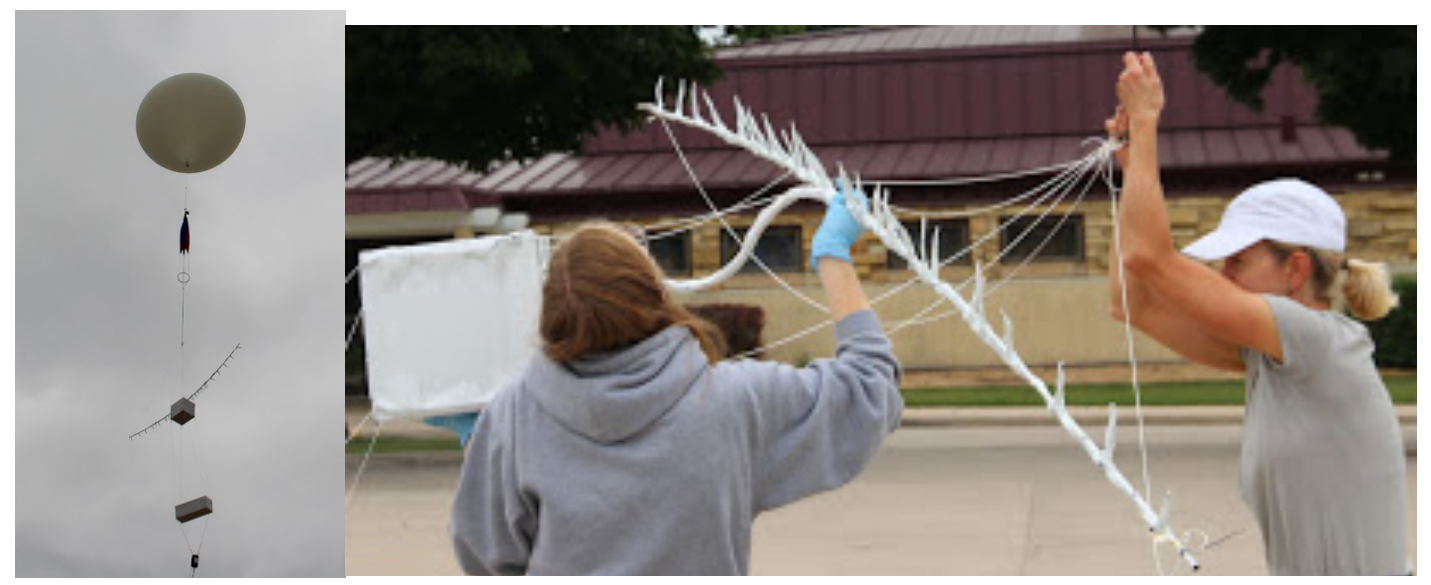

Fig. 4. The wake boom: Left side picture is a boom in flight and right is structure in preparation for flight. There is a $30 \mathrm{~cm}$ gap between the boom and the top of logging payload [22]. 
If the balloon is to stay in thermal equilibrium with the surrounding environment, adiabatic expansion during ascent requires $11.9 \mathrm{kWs}$ of energy transfer for each $1 \mathrm{~K}$ change in balloon temperature, based on helium-filled balloons with an initial volume of $14.13 \mathrm{~m}^{3}$. The air through which the balloon ascends supplies this heat. Assuming an ascent rate of $6 \mathrm{~m} / \mathrm{s}$ and using temperatures measured during a night flight with our wake boom, the results shown in Table 2 give estimates of the cross sectional size of the thermal wake. As described by Tiefenau [12], night flight data are cleaner since radiation effects from the sun heating the skin of the balloon is not a factor. Based on these thermal wake areas, the $3.2 \mathrm{~m}$ maximum spacing of sensors on the wake boom appears large enough to sample the entirety of the thermal wake except at the highest altitudes.

\begin{tabular}{|c|c|c|c|c|c|c|c|c|}
\hline $\mathrm{A}$ & B & $\mathrm{C}$ & $\mathrm{D}$ & E & $\mathrm{F}$ & G & $\mathrm{H}$ & I \\
\hline$(\mathrm{km})$ & $(\mathrm{hPa})$ & $(\mathrm{kW})$ & $(\mathrm{K})$ & $\left(\mathrm{m}^{3} / \mathrm{s}\right)$ & $\left(\mathrm{m}^{2}\right)$ & $\left(\mathrm{m}^{2}\right)$ & $\left(\mathrm{m}^{3} / \mathrm{s}\right)$ & $(\mathrm{K})$ \\
\hline 10 & 264.36 & 0.95 & 0.10 & 22.89 & 3.81 & 0.64 & 1.22 & 0.61 \\
\hline 20 & 54.75 & 1.43 & 1.20 & 13.41 & 2.23 & 2.34 & 0.96 & 1.16 \\
\hline 25 & 25.11 & 1.77 & 1.50 & 29.60 & 4.93 & 4.52 & 0.83 & 1.67 \\
\hline 30 & 11.72 & 2.15 & 2.30 & 51.55 & 8.59 & 8.59 & 0.72 & 2.34 \\
\hline $\mathrm{A}$ & \multicolumn{8}{|l|}{ Altitude } \\
\hline B & \multicolumn{8}{|l|}{ Pressure } \\
\hline $\mathrm{C}$ & \multicolumn{8}{|c|}{ Energy Flow Needed for Adiabatic Balloon Expansion per K temperature change } \\
\hline $\mathrm{D}$ & \multicolumn{8}{|c|}{ Measured Wake Temperature Drop - Flight 4N } \\
\hline $\mathrm{E}$ & \multicolumn{8}{|c|}{ Required Thermal Wake Volume Flow rate to transfer heat using C and D } \\
\hline F & \multicolumn{8}{|c|}{ Thermal Wake Cross Section from E based on $6 \mathrm{~m} / \mathrm{s}$ ascent rate } \\
\hline G & \multicolumn{8}{|c|}{ Thermal Wake Cross Section calculated using $\mathrm{d} \approx 1 /(\sqrt{\mathrm{P}})$ heat exchange layer } \\
\hline $\mathrm{H}$ & \multicolumn{8}{|c|}{ Thermal Wake Volume Flow from $\mathrm{d} \approx 1 /(\sqrt{\mathrm{P}})$ to transfer heat using $\mathrm{C}$ and $\mathrm{D}$} \\
\hline I & \multicolumn{8}{|c|}{ Calculated Temperature Drop from $\mathrm{C}$ and $\mathrm{H}$} \\
\hline
\end{tabular}

Table 2: Values used to estimate the size of the thermal wake for a night flight using the methods of Tiefenau [12]. Calculations are normalized to $30 \mathrm{~km}$. Calculated thermal wake temperature drops, Column I, compare well with measured results shown in Column D.

\section{Methods}

The eclipse day launch location in Aurora, Nebraska, experienced 2 minutes and 35 seconds of totality beginning at 13:01 CDT. To characterize the atmosphere prior to eclipse day, we flew four balloons with wake booms - two balloons on Aug. $19^{\text {th }}$ and two balloons on Aug. $20^{\text {th }}$. During the eclipse we launched two balloons with wake booms for a total of six balloons launched within a 48-hour window prior to and during the eclipse. All of the flight launches were conducted between 11:30 CDT and 12:30 CDT. As Ramkumar [2] states, "reducing the diurnal temperature variation effects are an important consideration when dealing with this type of data." The path of totality and the flight paths of the balloons flown during the eclipse are shown in Fig. 5. The details of flights are given in Table 3. 


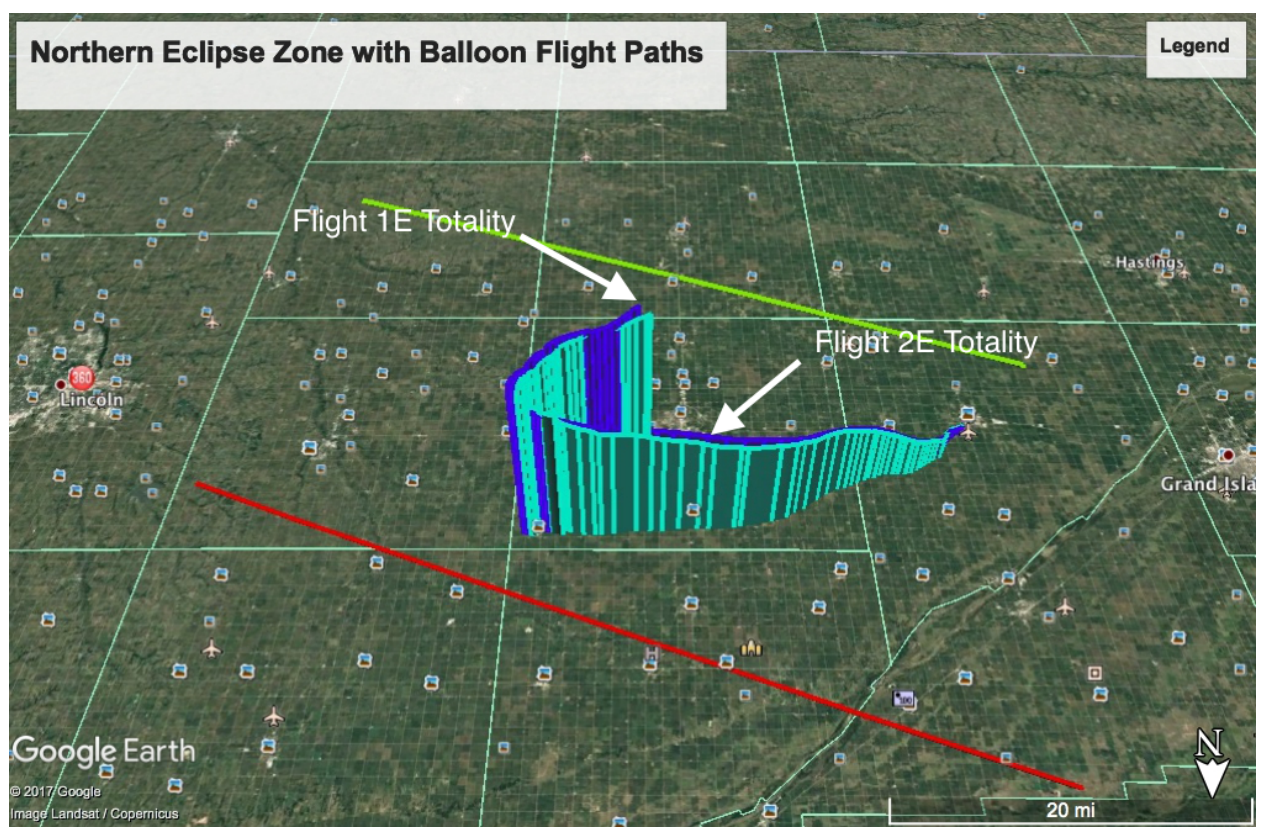

Fig. 5: Eclipse totality and HAB flight paths in central NE on August $21^{\text {st }}, 2017$. The yellow line is the center of the path of totality and the red line is the northern edge of totality. Note that north points downward for a clearer view of the flight paths. The time of totality is also indicated - just post burst for flight $1 \mathrm{E}$ and mid-ascent for flight

2E.

We tested different off-the-shelf temperature measuring systems to determine which are suitable for use in this work [9, 18]. Early tests [5] included a variety of sun shrouds and it was determined that even with well-ventilated sun shrouds the measured temperature was warmer than un-shrouded sensors. The shrouded sensors also demonstrated a time lag - i.e. registering balloon burst 3-4 seconds post burst compared to open-air sensors. As a result, our temperature sensors are flown un-shrouded. In addition, a series of tests conducted with painted and unpainted sensors determined that a flat white paint would be used on all temperature sensors. Brasefield [11] conducted similar tests where he determined that white painted sensors reflect up to $90 \%$ of solar radiation.

Based on cost, flexibility, and performance in the low temperature and pressure conditions experienced during a HAB flight, we currently use two types of temperature sensors: Maxim DS18B20 digital band-gap temperature sensors logged every four seconds by an Arduino Mega microcontroller, and Onset HOBO thermistor temperature sensors logged every two seconds by an Onset U12-013 data logger $[7,9,19]$. The temperature sensors, mounted on the wake boom, are suspended approximately $6 \mathrm{~m}$ below the neck of the balloon, within the thermal wake region and above the payload boxes. The boom is centered beneath the balloon to measure thermal wake asymmetries and attached to the balloon neck to minimize swing. Barat [10] states that radiosonde payloads swing in and out of the thermal wake but we have video evidence that our wake boom swings very little; staying within the thermal wake.

Ground tests have shown sensor-to-sensor variability up to $\pm 0.5^{\circ} \mathrm{C}$ at room temperature and pressure and up to $\pm 2{ }^{\circ} \mathrm{C}$ at $-40^{\circ} \mathrm{C}$ and $10 \mathrm{hPa}$ pressure - closer to the conditions experienced during stratospheric flights. To account for sensor-to-sensor variation, each sensor goes through a calibration process [19, 20]. In this process, each sensor is calibrated against a NIST-certified thermocouple at two different temperatures and at low pressure to create a sensor unique, linear calibration curve to correct this variability. After a flight, data from each sensor are analyzed using the calibration curve for the particular sensor. Through this calibration process we are able to measure even potentially small temperature variations as part of the thermal-wake effect [19]. However, as pointed out by Flaten [21], "temperature measurements are prone to many sources of error, one of those being the fact that measured temperatures will by definition lag the actual raw temperature (when used in a constantly-changing-temperature environment)." 


\begin{tabular}{|c|c|c|c|c|c|c|c|}
\hline $\begin{array}{c}\text { Flight } \\
\text { Number }\end{array}$ & Date & $\begin{array}{l}\text { Launch } \\
\text { Site }\end{array}$ & Equipment & $\begin{array}{l}\text { Burst } \\
\text { Altitude } \\
\text { (m) }\end{array}$ & $\begin{array}{l}\text { Burst Time } \\
\text { (CDT) }\end{array}$ & $\begin{array}{c}\text { Recovery } \\
\text { Site }\end{array}$ & $\begin{array}{c}\text { Altitude at } \\
\text { start of } \\
\text { totality } \\
\end{array}$ \\
\hline $4 \mathrm{~N}$ & $8-4-2016$ & $\begin{array}{l}\text { Madelia, } \\
\text { MN }\end{array}$ & $\begin{array}{c}\text { 22xDS18B20 } \\
\text { 9xHOBO } \\
\text { 1D } \\
\text { 1D Wake Arm }\end{array}$ & 33,385 & $0: 53$ & $\begin{array}{l}\text { Waseca, } \\
\text { MN }\end{array}$ & $\mathrm{N} / \mathrm{A}$ \\
\hline $13 \mathrm{D}$ & 8-19-2017 & $\begin{array}{l}\text { Grand } \\
\text { Island, } \\
\text { NE }\end{array}$ & $\begin{array}{c}22 \times D S 18 B 20^{(\mathrm{c})} \\
9 \times \mathrm{XOBO}^{(\mathrm{d})} \\
\text { 1D Wake Arm }\end{array}$ & 32,716 & 13.02 & $\begin{array}{l}\text { Hampton, } \\
\text { NE }\end{array}$ & $\mathrm{N} / \mathrm{A}$ \\
\hline $14 \mathrm{D}$ & 8-19-2017 & $\begin{array}{l}\text { Grand } \\
\text { Island, } \\
\text { NE }\end{array}$ & $\begin{array}{c}22 \times D S 18 B 20^{(c)} \\
9 \times H^{(d)} \\
\text { 1D Wake Arm }\end{array}$ & 31,588 & $14: 07$ & $\begin{array}{l}\text { Hampton, } \\
\text { NE }\end{array}$ & N/A \\
\hline $15 \mathrm{D}$ & $8-20-2017$ & $\begin{array}{c}\text { Aurora, } \\
\text { NE }\end{array}$ & $\begin{array}{c}22 \times D_{18 B 20}^{(c)} \\
9 \times H^{(c)}{ }^{(d)} \\
\text { 1D Wake Arm }\end{array}$ & 31,793 & $12: 52$ & $\begin{array}{l}\text { Gresham, } \\
\text { NE }\end{array}$ & $\mathrm{N} / \mathrm{A}$ \\
\hline $16 \mathrm{D}$ & $8-20-2017$ & $\begin{array}{c}\text { Aurora, } \\
\text { NE }\end{array}$ & $\begin{array}{c}22 \times D S 18 B 20^{(c)} \\
9 \times H^{(d)} \\
\text { 1D Wake Arm }\end{array}$ & 29,820 & $14: 04$ & $\begin{array}{l}\text { Gresham, } \\
\text { NE }\end{array}$ & $\mathrm{N} / \mathrm{A}$ \\
\hline $1 \mathrm{E}$ & $8-21-2017$ & $\begin{array}{l}\text { Aurora, } \\
\text { NE }\end{array}$ & $\begin{array}{c}22 \times D S 18 B 20^{(c)} \\
9 \times H^{(d)} \\
\text { 1D Wake Arm }\end{array}$ & 30,138 & $12: 55$ & $\begin{array}{l}\text { Garrison, } \\
\text { NE }\end{array}$ & $\begin{array}{c}18 \mathrm{~km} \\
\text { (post-burst) }\end{array}$ \\
\hline $2 \mathrm{E}$ & $8-21-2017$ & $\begin{array}{c}\text { Aurora, } \\
\text { NE }\end{array}$ & $\begin{array}{c}22 \times D S 18 B 20^{(c)} \\
9 x H O B O \\
\text { 1D } \\
\text { Dake Arm }\end{array}$ & 31,494 & $13: 49$ & $\begin{array}{l}\text { Garrison, } \\
\text { NE }\end{array}$ & $\begin{array}{c}14 \mathrm{~km} \\
\text { (ascending) }\end{array}$ \\
\hline
\end{tabular}

Table 3: Summary of pre-eclipse and eclipse day balloon launches. "N" denotes a nighttime flight, "D" denotes a daytime flight and "E" denotes a flight during the eclipse.

(a) DS18B20 sensors on wake boom at 10, 20, 30, 40, 50, 60, 70, 80, 90, 100 and $110 \mathrm{~cm}$ - both sides.

(b) HOBO sensors on wake boom at 10, 20, 30, 40 50, 60, 70, 90 and $100 \mathrm{~cm}-$ one side.

(c) DS18B20 sensors on wake boom at 10, 20, 30, 40, 50, 60, 80, 100, 120, 140 and $160 \mathrm{~cm}$ - both sides.

(d) HOBO sensors at 5, 25 and $45 \mathrm{~cm}$ on one side of the boom and 15, 35 and $65 \mathrm{~cm}$ on the other side of the boom

\section{Results}

Fig. 6 shows altitude profiles of the temperature for the night flight, the four daytime flights conducted on the days preceding the eclipse, as well as the two flights conducted on the day of the eclipse. The plot on the top shows temperature data from the entirety of ascent and the plot on the bottom shows data above $10 \mathrm{~km}$. Note that the data from different flights show less than a $5{ }^{\circ} \mathrm{C}$ difference in the troposphere, but begin to diverge once the balloon enters the tropopause at approximately $14 \mathrm{~km}$ altitude, where two different profiles become evident and the temperature difference increases to nearly $15{ }^{\circ} \mathrm{C}$. The three profiles on the left, the lower temperature grouping, belong to the night flight and the two eclipse flights. The four daytime, pre-eclipse flights make up the higher temperature grouping on the right side. It is clear from these groupings that eclipse day atmospheric temperatures plotted as a function of altitude are more similar to the night flight than the pre-eclipse day flights. 

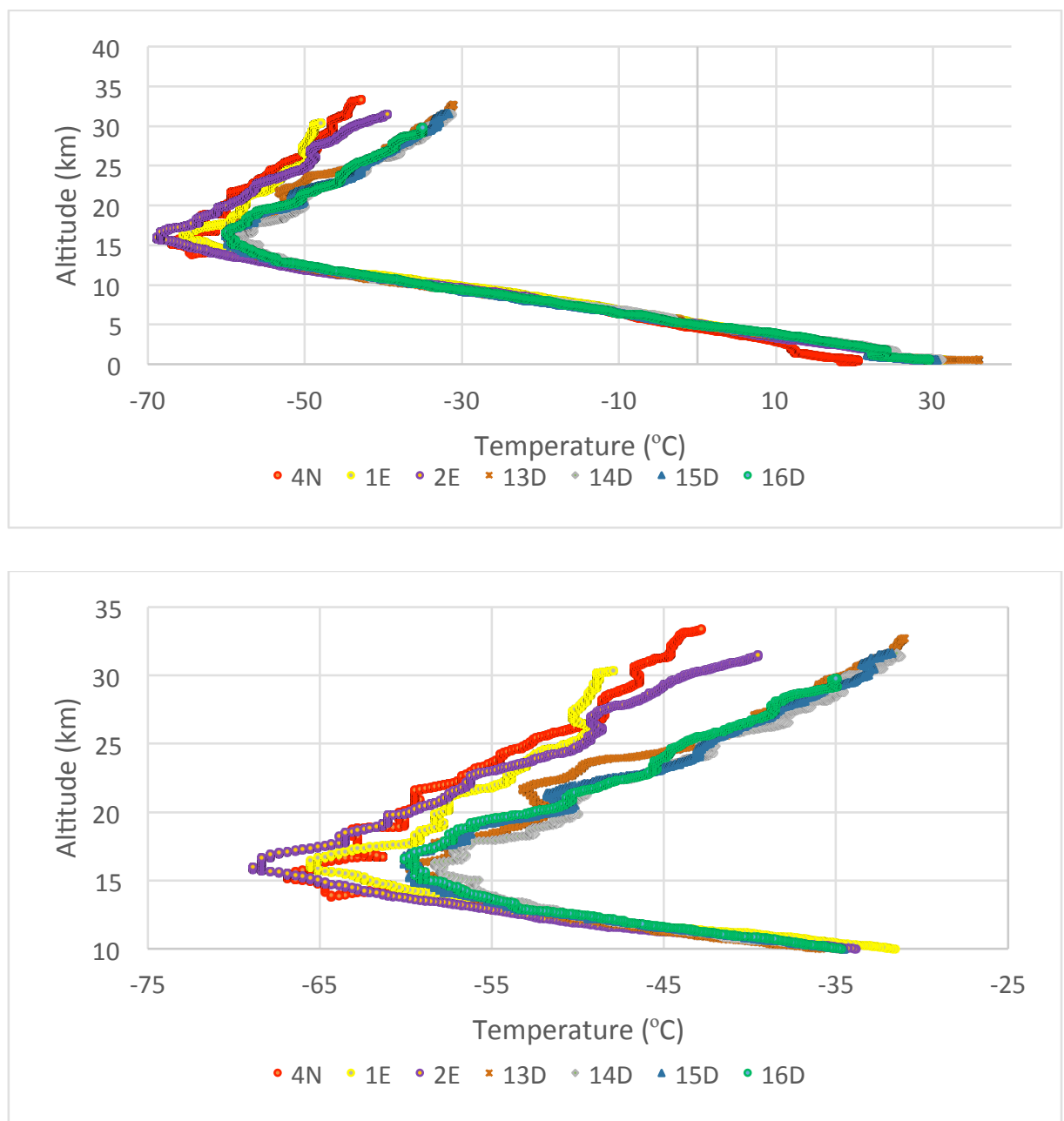

Fig. 6: Top - Altitude versus Temperature (HOBO sensors) for flights listed in Table 3. Bottom - Same data above $10 \mathrm{~km}$. . Flight $1 \mathrm{E}$ burst 6 minutes before totality and flight $2 \mathrm{E}$ was at an altitude of $14-15 \mathrm{~km}$ during totality.

In Fig. 7, we show calibrated DS18B20 temperature data plotted as a function of distance from the center of the wake boom for night flight $4 \mathrm{~N}$. Altitude slices of temperature data are shown from the troposphere, at $9 \mathrm{~km}$, and the stratosphere at 23.2 and $30.5 \mathrm{~km}$. The data show an increasing cool thermal wake effect as the balloon ascends in altitude into the nighttime stratosphere. The cool wake is not visible in the $9 \mathrm{~km}$ data, demonstrated by the nearly horizontal temperature profile, but becomes more pronounced as the balloon ascends to $30.5 \mathrm{~km}$, showing an approximately $3{ }^{\circ} \mathrm{C}$ lower temperature in the center of the boom compared to the ends of the boom. Because the thermal wake is characteristic of decreasing pressure and a thickening heat exchange layer, one expects the effect to become more pronounced at increasing altitudes.

Fig. 8 is a plot of temperature differences measured across the wake boom during flight $4 \mathrm{~N}$. The differences are shown for stratospheric data, where the thermal wake becomes significant. The difference is calculated by subtracting the average temperature of the two outermost sensors on the wake boom from the average temperature of the ten sensors located across the central $100 \mathrm{~cm}$ of the wake boom. From this plot, it is clear that the thermal wake effect becomes more pronounced as the balloon ascends into the stratosphere, indicated by the increasing negative temperature difference. 


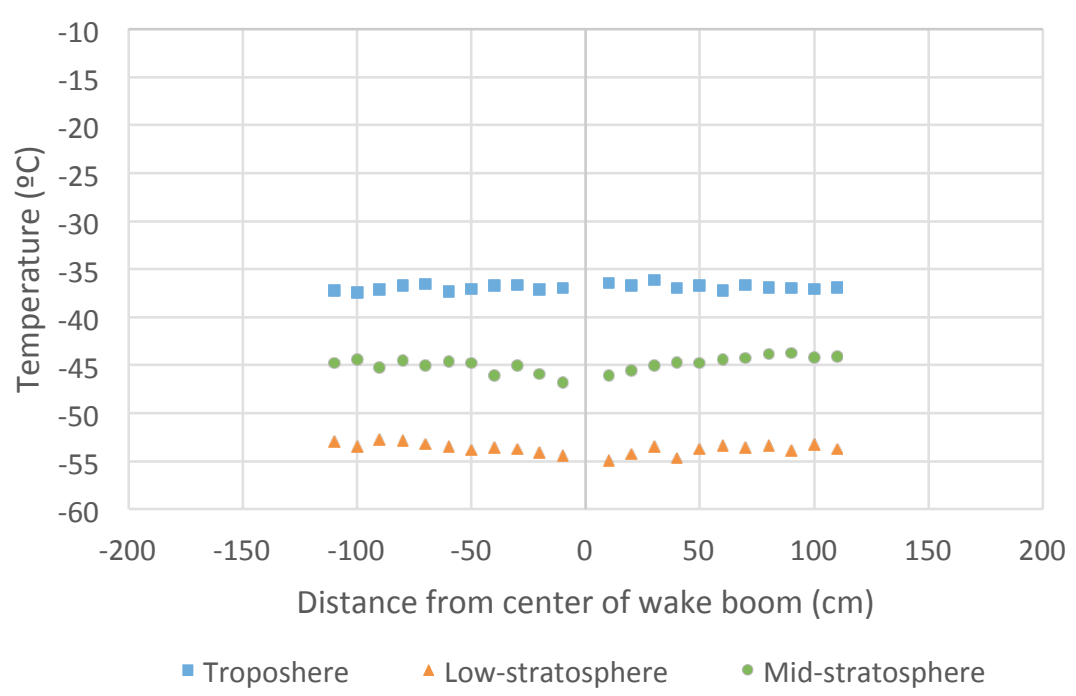

Fig. 7: Calibrated DS18B20 temperature data from flight 4N using a $2.2 \mathrm{~m}$ wake boom. Data are plotted to illustrate how the temperature varies across the wake boom. Cooling is enhanced in the center of the wake with increasing altitude as predicted by Tiefenau [12]. Troposphere data (warmest) are at $9 \mathrm{~km}$, low-stratosphere data (coldest) at $23.2 \mathrm{~km}$ and mid-stratosphere data (middle) at $30.5 \mathrm{~km}$.

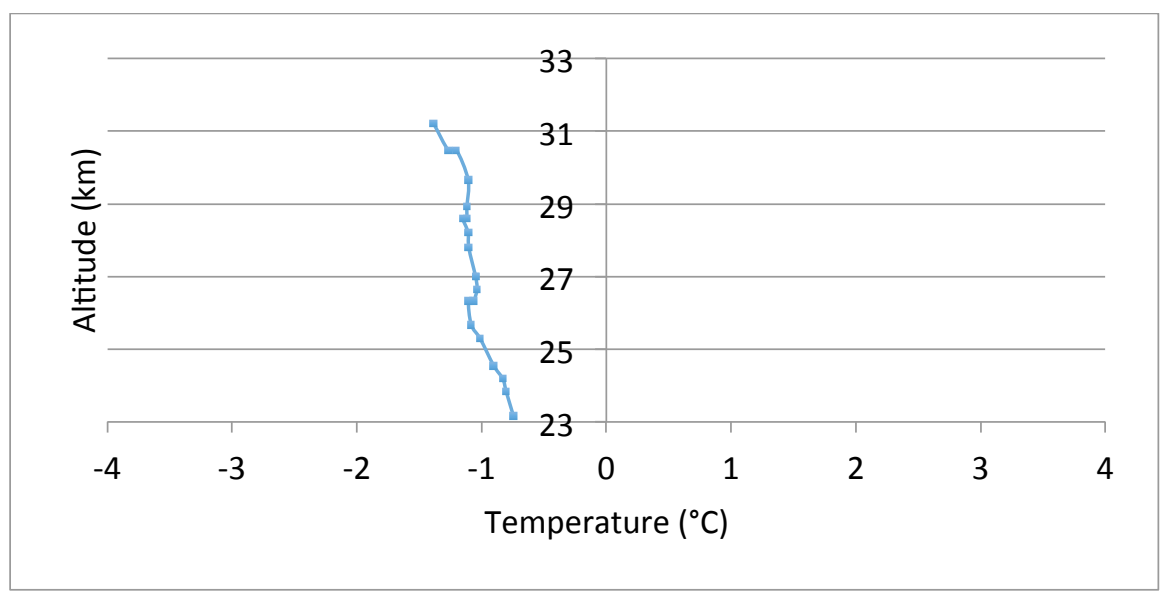

Fig. 8: 4N flight showing a negative temperature (DS18B20) difference between the average temperature measured across the central $100 \mathrm{~cm}$ of the wake boom and the average temperature measured by the outermost sensors. The negative difference indicates that it is cooler within the thermal wake directly beneath the balloon.

Data collected from 13D, 14D, 15D and 16D (pre-eclipse day flights) show a different thermal wake profile with warmer temperatures beneath the neck of the balloon and cooler temperatures as one moves outward horizontally along the boom. In addition to the thermal wake, the data occasionally shows a temperature spike associated with solar heating of the nearby logger box - a "box proximity effect." Clearly, thermal effects from nearby objects complicate temperature measurements. In Fig. 9, we removed data points between 10 and $40 \mathrm{~cm}$; those affected by the presence of the box. The sensor located at $130 \mathrm{~cm}$ did not function properly so that data is also removed. 


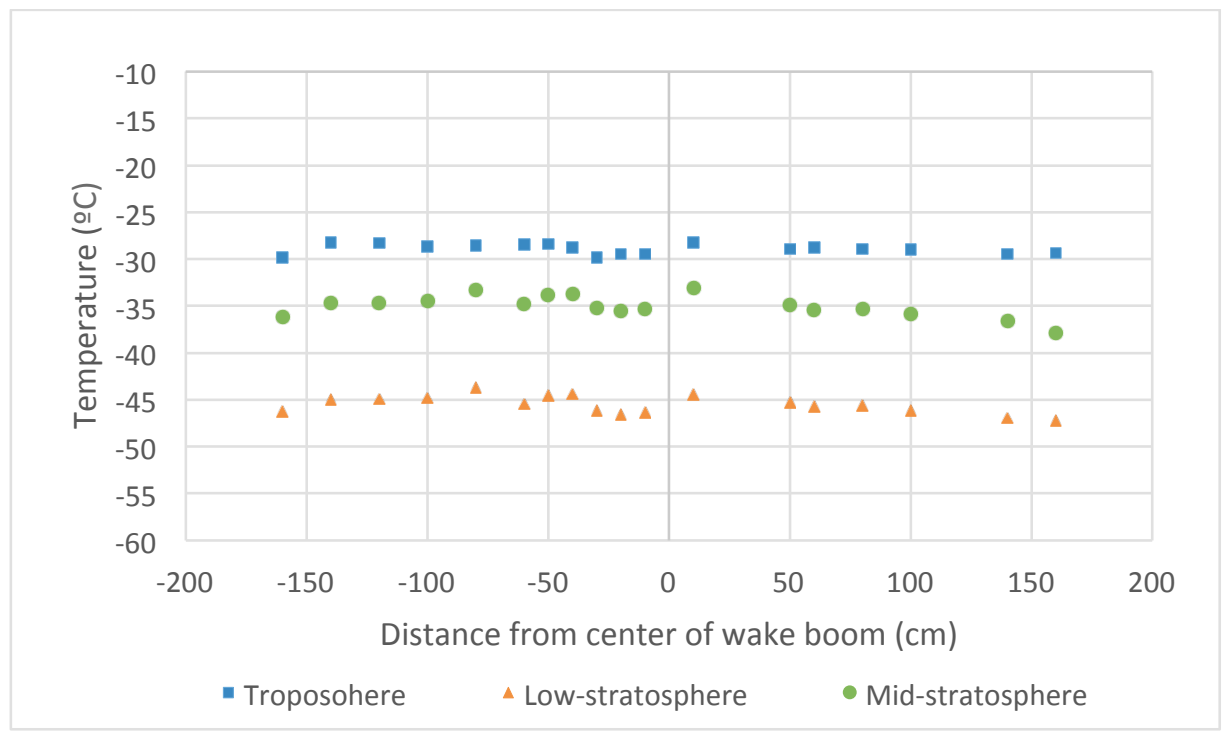

Fig. 9: Calibrated DS18B20 wake boom temperature data from flight 16D shows a pre-eclipse daytime flight with a warmer region in the center as compared to outer sensors. Troposphere data (warmest) are at $9 \mathrm{~km}$, low-stratosphere data (coldest) at $23 \mathrm{~km}$ and mid-stratosphere data (middle) at $29.8 \mathrm{~km}$.

Fig. 10 is a plot of temperature differences across the wake boom measured during flight $16 \mathrm{D}$. The calculations are completed in the same manner as Fig. 8. From this plot it is clear that the warm thermal wake effect becomes more pronounced as the balloon ascends into the stratosphere, shown by the increasing positive temperature difference at higher altitudes. The positive temperature difference is opposite of that seen for flight $4 \mathrm{~N}$. This positive difference means it was warmer in the $100 \mathrm{~cm}$ directly beneath the balloon relative to the sensors on the end of the boom.

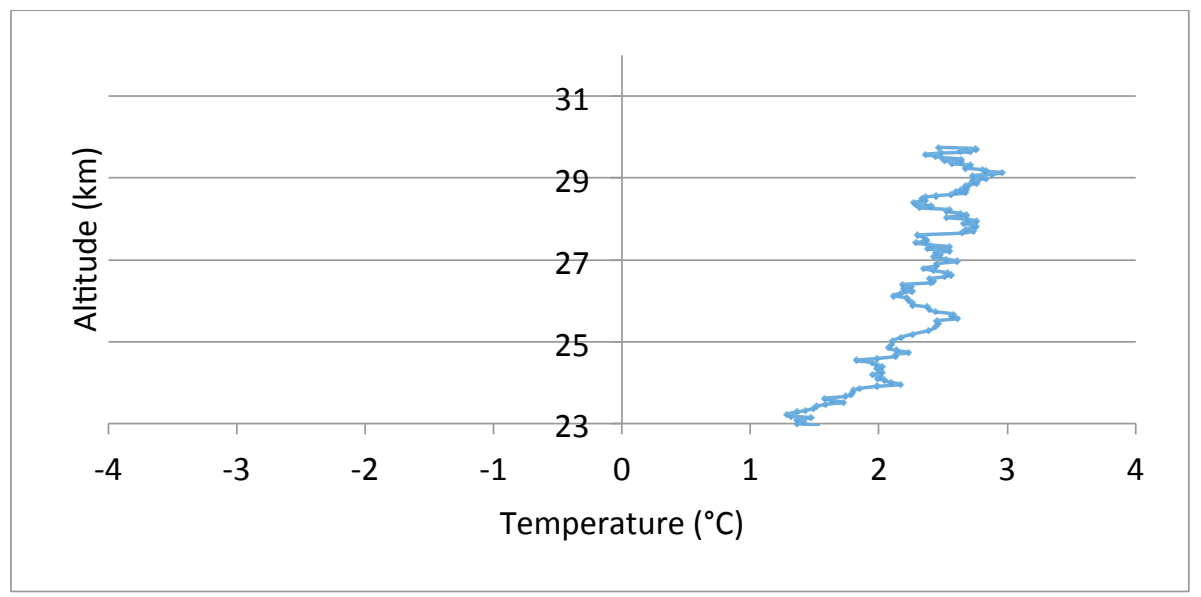

Fig. 10: 16D flight showing a positive temperature (DS18B20) difference between the average temperature measured across the central $100 \mathrm{~cm}$ of the wake boom and the average temperature measured by the outermost sensors. The positive difference indicates that it is warmer beneath the balloon. This increasing positive result agrees with Tiefenau [12], that wake effects increase as the heat exchange layer thickness grows with decreasing pressure.

Fig. 11 shows DS18B20 data from flight 1E with altitude slices corresponding to $9 \mathrm{~km}, 23 \mathrm{~km}$ and $30 \mathrm{~km}$. These slices show expected behaviors, overall cooling followed by warming temperatures as the balloon ascends into the stratosphere. Compared to non-eclipse day, and night flights, this data does not show a warm or cool thermal wake effect that grows more pronounced as the balloon ascends. Fig. 12 supports this conclusion, as the temperature difference between the central and outer sensors is nearly constant as the balloon ascends into the stratosphere. The 
slight positive temperature difference makes sense, as even during a total eclipse there is more solar energy present than during a night flight resulting in some warming of the balloon skin.

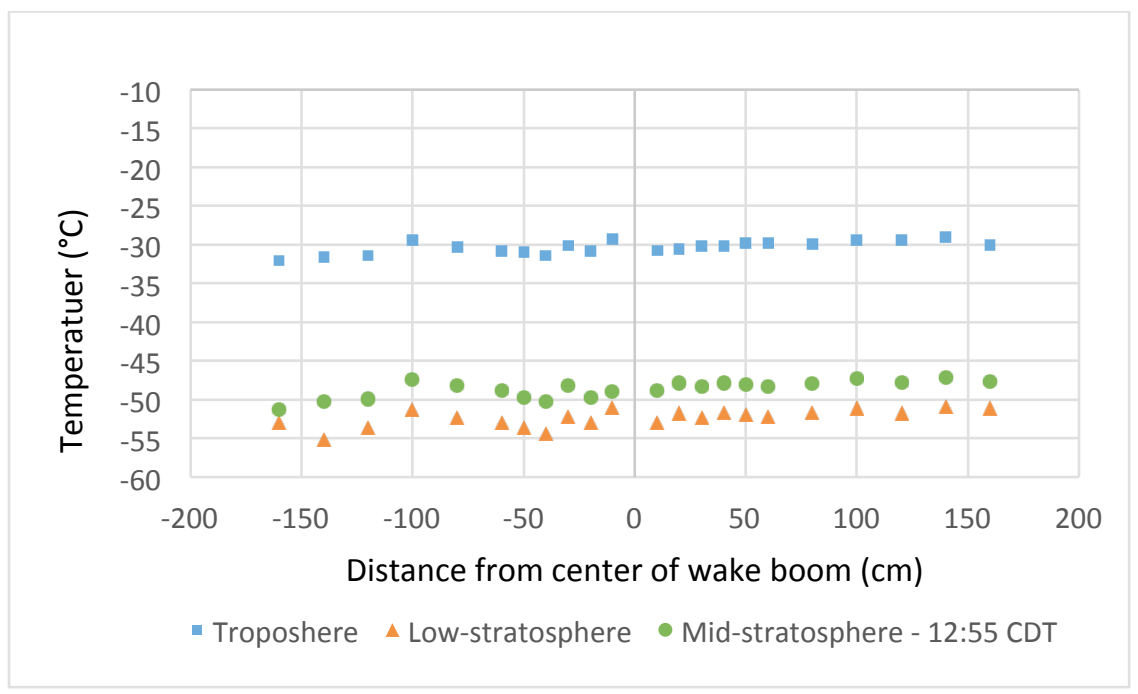

Fig. 11: Calibrated DS18B20 wake boom temperature data from flight 1E, an eclipse flight. Troposphere data (warmest) are at $9 \mathrm{~km}$, low-stratosphere data (coldest) at $23 \mathrm{~km}$ and mid-stratosphere data (middle) at $30 \mathrm{~km}$. The $30 \mathrm{~km}$ data occurs at 12:55 CDT, six minutes before totality. Missing from this data: a clearly increasing positive or negative thermal wake effect as the balloon ascends into the stratosphere.

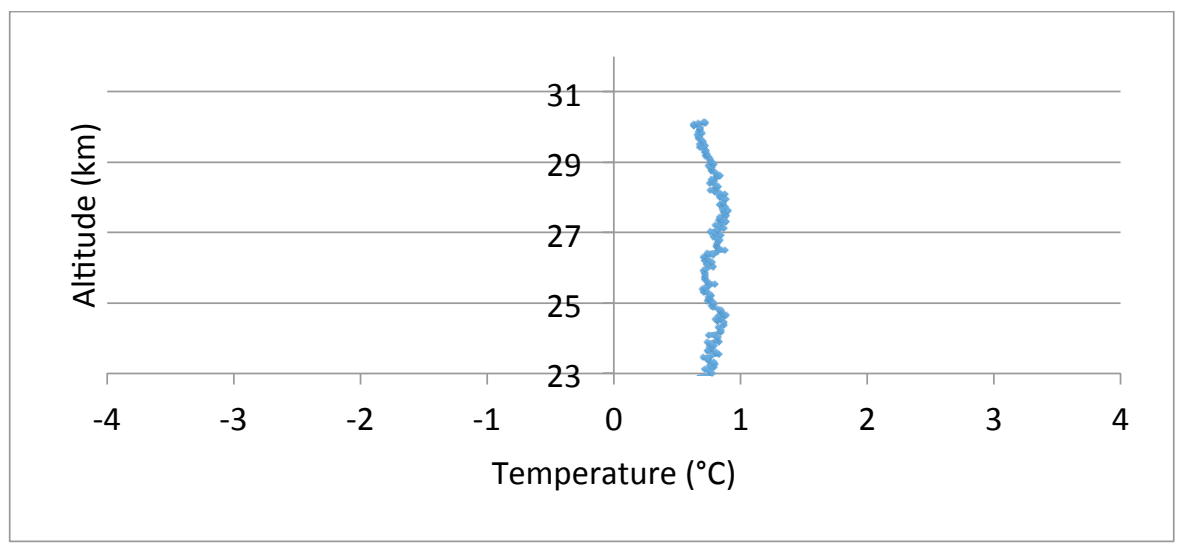

Fig. 12: 1E stratospheric temperature (DS18B20) difference between the average temperature measured across the central $100 \mathrm{~cm}$ of the wake boom and the average temperature measured by the outermost sensors. Compared to the night and day flights shown in Fig. 8 and Fig. 10, the temperature difference across the wake boom is nearly flat, indicating no significant positive or negative temperature difference across the thermal wake profile.

Fig. 13 shows DS18B20 temperature data for flight 2E plotted at $9 \mathrm{~km}, 23 \mathrm{~km}$ and $30 \mathrm{~km}$. Note once again the nearly horizontal nature of the temperature data across the wake boom until the balloon reaches its maximum altitude (middle data line) where slight warming in the center of the wake boom becomes evident. Fig. 14, the difference plot for flight $2 \mathrm{E}$ supports the conclusion that the temperature profiles were nearly flat during this eclipse flight. The slight warming that becomes evident after $26 \mathrm{~km}$ is over 25 minutes after totality. 


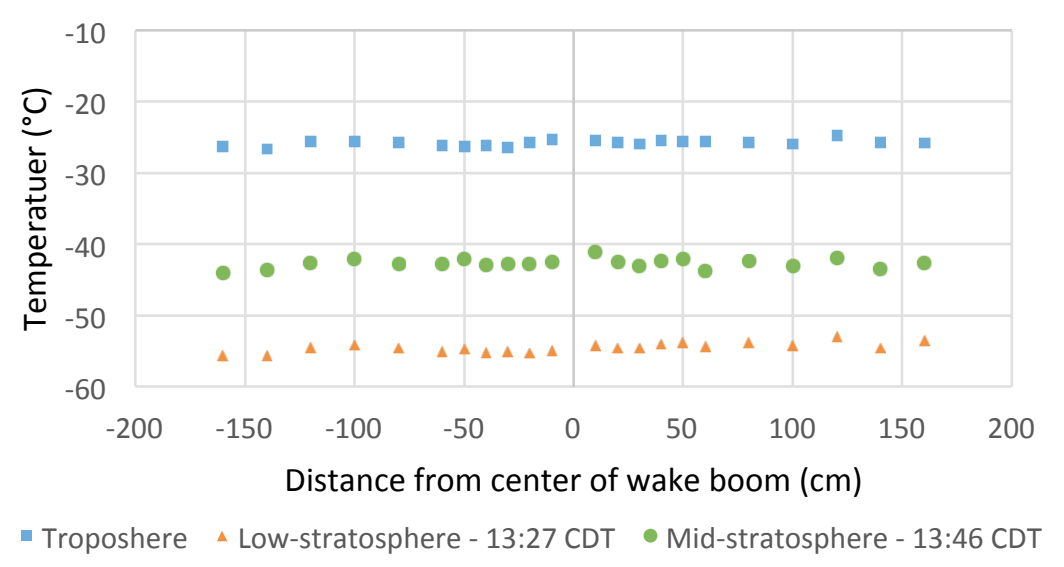

Fig. 13: Calibrated DS18B20 wake boom temperature data from flight 2E showing temperature data during the eclipse $-9 \mathrm{~km}$ data (warmest) at five minutes before totality, $23 \mathrm{~km}$ data (coldest) at 23 minutes after totality and 30 $\mathrm{km}$ data (middle) at 42 minutes after totality.

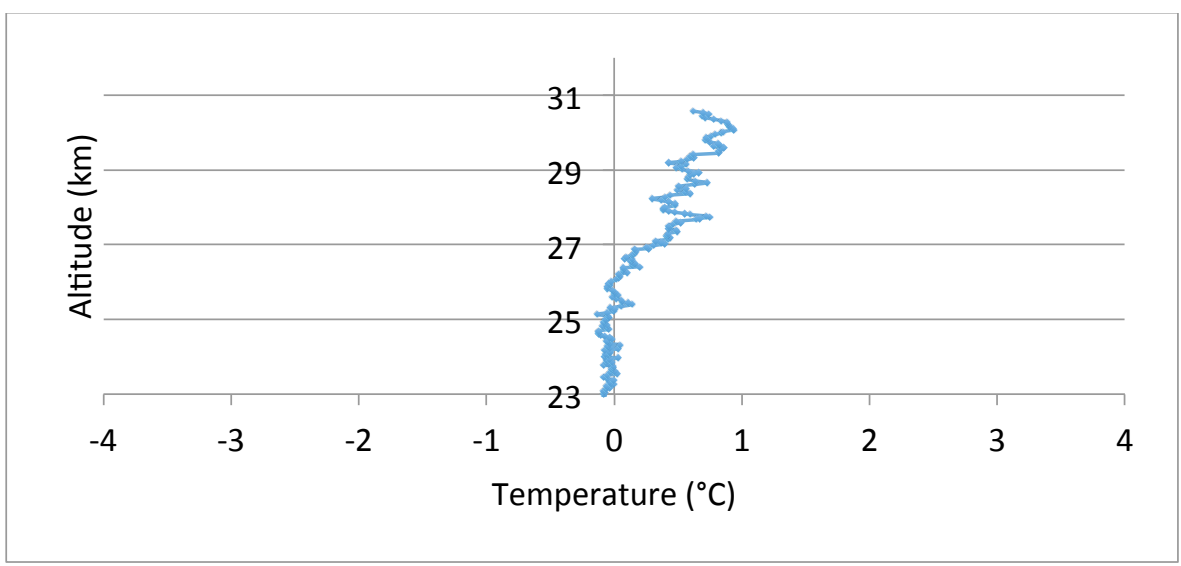

Fig. 14: 2E stratospheric temperature (DS18B20) difference showing that wake boom profiles were nearly flat well past totality. A slight warming begins at $26 \mathrm{~km}$ altitude, approximately 25 minutes after totality.

The nearly zero temperature difference between 23 and $26 \mathrm{~km}$ in Fig. 14 (2E) is noticeably different from the approximately $1^{\circ} \mathrm{C}$ positive temperature difference in Fig. 12 (1E) and worth discussing. Referring back to Fig. 6 it is clear that flight $2 \mathrm{E}$ experienced colder atmospheric temperatures relative to flight $1 \mathrm{E}$ up to approximately $24 \mathrm{~km}$. From 24 to $26 \mathrm{~km}$ flight $2 \mathrm{E}$ was only slightly warmer than flight $1 \mathrm{E}$, but past $27 \mathrm{~km}$, flight $2 \mathrm{E}$ experienced temperatures that were significantly warmer than flight $1 \mathrm{E}$. We believe the cooler atmospheric temperatures during flight $2 \mathrm{E}$ reduced the amount of thermal energy available to a point where balloon cooling by adiabatic expansion was in balance with the available solar energy, resulting in a thermal wake of nearly uniform temperature up to 26 $\mathrm{km}$. At $26 \mathrm{~km}$, twenty-five minutes after totality, the atmosphere begins to show warming relative to the coolest eclipse temperatures. The result is wake temperature profiles typical of a daytime flight and positive temperature differences across the wake boom.

\section{Conclusions}

Fig. 15 plots temperature differences at $1 \mathrm{~km}$ increments calculated using wake boom HOBO temperature averages. Data on the left side are night and eclipse flights compared to $16 \mathrm{D}$, a daytime pre-eclipse flight, and clearly indicate a negative temperature difference that increases as the balloon ascends. When the eclipse flight data are compared in the same way to the $4 \mathrm{~N}$ night flight data, one sees a small negative temperature differential up to approximately $17 \mathrm{~km}$ and then a positive differential up to $25 \mathrm{~km}$. After cooling to $27 \mathrm{~km}$ eclipse flight $1 \mathrm{E}$ cools even more but flight $2 \mathrm{E}$ warms, possibly because totality had passed and the atmosphere was beginning to warm. 


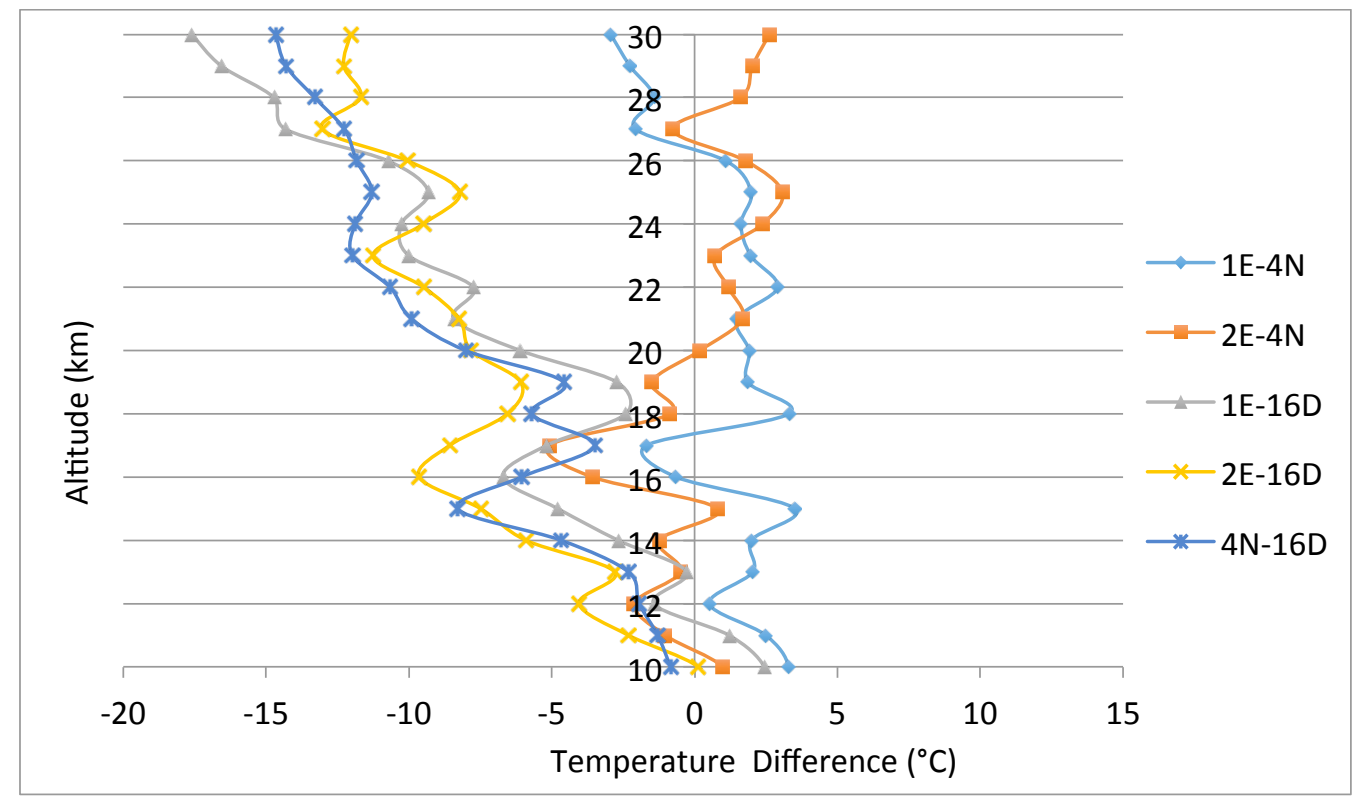

Fig. 15: Temperature difference profiles using averages measured by HOBO sensors, plotted at $1 \mathrm{~km}$ increments. The differences compare eclipse flight data to night and day flight results. The differences support the conclusions that eclipse temperatures; measured at all altitudes were more similar to temperatures measured at night than during the day.

These results agree with findings published by Ramkumar et al. [2] for cooling observed in the stratosphere during a total solar eclipse. In addition, flights $1 \mathrm{E}$ and $2 \mathrm{E}$ show neither typical daytime wake nor nighttime wake temperature profiles, instead, the profiles appear nearly flat - an eclipse thermal wake. Given the large number of sensors and flights both before and during the eclipse, we conclude that the $1 \mathrm{E}$ and $2 \mathrm{E}$ eclipse wake temperature profiles are directly related to cooling of the atmosphere and the balloon skin during the solar eclipse. Finally, as we have discussed in previous works, accurately measuring temperature from balloons ascending in the stratosphere is complicated due to dramatic changes in temperature and pressure, the fact that we are moving through a nonconstant temperature environment, and thermal radiation effects of nearby objects. Indeed, it is solar thermal radiation that produces the very effect we are trying to characterize, the thermal wake.

\section{Acknowledgments}

We are grateful for support received over the past four years. We are thankful for the St. Catherine University administration and alumni for funding the Summer Scholars program to support student hours during the summers of 2014 (as well as supplies) and 2017. We also wish to thank the Henry Luce Foundation as part of the Clare Booth Luce (CBL) program to enhance undergraduate research opportunities for women majoring in Physics, Mathematics, and Chemistry. We received support from CBL during the 2014-15 academic year. We also wish to thank the Denny family for the Carol Easley Denny award which provided student hours and supplies for the 201516 academic year. We also wish to thank the Assistant Mentorship Program, which supported student hours during 2016 and 2017. since 2007.

We would also like the Minnesota Space Grant Consortium for financial support of ballooning activities

UMM would like to thank the Morris Academic Partnerships program as well as the UMM Faculty Research Enhancement Funds. 


\section{References}

[1] Eckerman, S., Broutman, D., Stollberg, M. T., Ma, J., McCormack, J. P, and Hogan T. F., "Atmospheric effects of the total solar eclipse of 4 December 2002 simulated with a high-altitude global model," J. Geo. Res., 2007.

[2] Ramkumar, T.K., Ghosh, P., Reddy, K., Kumar, K. N., Kumar, S.B., Reddy, A. H., Reddy, M. V., and Prasad, S., "Large scale anomalous temperature and wind variations in the lower and middle atmospheres during the solar eclipse of 15 January 2010,” Indian J. of Radio and Space Physics, India, 2014.

[3] Harrison, R.G., Marlton, G.J., Williams, G.J., and Nicoll, K.A., "Coordinated weather balloon solar radiation measurements during a solar eclipse," Phil. Tans. R. Soc. A 37420150221.

[4] Marlton, G.J., Williams, P.D., and Nicoll, K.A., "On the detection and attribution of gravity waves generated by the 20 March 2015 solar eclipse," Phil. Tans. R. Soc. A 37420150222.

[5] Agrimson, E. and Flaten, J., "Using HOBO data loggers with Air/Water/Soil temperature probes to measure free-air temperature on high-altitude balloon flights," Annual Academic High Altitude Conference (AHAC) proceedings, Tennessee, 2012, pp. 20-31.

[6] Hedden, R., Blish, M., Grove, A., Agrimson, E., and Flaten, J., "High Altitude Thermal Wake Investigation," AHAC Proceedings, Indiana, 2013.

[7] Agrimson, E., Smith, K., Flaten, J., Blish, M., Newman, R., White, J., Singerhouse, M., Anderson, E., McDonald, S., Gosch, C., and Pratt, A., "Continued Exploration of the Thermal Wake Below Ascending HighAltitude Balloons," AHAC proceedings, North Dakota, 2014.

[8] Blish, M., Hedden, R., White, J., Grove, A., Agrimson, E., Flaten, J., and McDonald, S., "Stratospheric High Altitude Balloon Thermal Wake Investigation," American Association of Physics Teachers meeting, winter 2014, Orlando FL. Poster.

www.aapt.org/docdirectory/meetingpresentations/WM14/AAPT\%20poster\%20St.Catherine\%20University_Agr imson.ppt

[9] Agrimson, E., Smith, K., Newman, R., Surma, K., Singerhouse, M., Craig, B., McNamara, M., Flaten, J., Pratt, A., Wegner, S., and Dillon, J., "Using Thermocouple, Thermistor, and Digital Sensors to Characterize the Thermal Wake Below Ascending Weather Balloons," AHAC proceedings, Illinois, 2015.

[10] Barat, J., Cot, C., and Sidi, C., "On the Measurement of the Turbulence Dissipation Rate from Rising Balloons," J. of Atmos. And Oceanic Tech. 1, (270-275) 1984.

[11] Brasefield, C.J., "Measurement of air temperature in the presence of solar radiation," J. Meteor., 5 (147-151), 1948.

[12] Tiefenau, H. and Gebbeken, A., "Influence of meteorological balloons on Temperature Measurements with Radiosondes: Nighttime Cooling and Daylight Heating," J. Atmos. and Oceanic Tech. 6 (36-42), 1989.

[13] Ney, E., Maas, R., and Huch, W., "The measurement of atmospheric temperature," J. Meteor., 18 (60-80), 1960.

[14] Kräuchi, A., Philipona, R., Romanens, G., Hurst, D., Hall, E., and Jordan, A., "Controlled weather balloon ascents and descents for atmospheric research and climate monitoring," Atmos. Meas. Tech. 9, (929-938), 2016.

[15] Jumper, G., Murphy, E., Strauss, D., and Beland, R., "Using temperature to detect wake contamination of thermosonde data," $33^{\text {rd }}$ AIAA Plasmadynamics and Lasers Conference, 20-23 May 2002, AIAA 2002-2275.

[16] http://www.braeunig.us/space/atmos.htm

[17] Eaton, F., Kelly, P., Kyrazis, D., and Stokes, S., "Refractivity turbulence observation using a new balloon-ring platform," 12 March 2002 Conference Proceedings, AFRL-DE-PS-TP-2207-1008.

[18] Kyrazis, D., Eaton, F., Black, L. D., Black, W., and Black, A., "The balloon ring: a high-performance low-cost instrumentation platform for measuring atmospheric turbulence profiles," 22 June 2009 Technical paper, AFRL-RD-PS-TP-2009-1011.

[19] Smith, K., Craig, B., Roith, J., Agrimson, E., and Flaten, J., “Accuracy and Precision of Temperature Sensors in the Stratosphere," AHAC, Minnesota, 2016. (Under review.)

[20] Agrimson, E., Smith, K., Onyango-Robshaw, V., Taylor, A., Lang, R., Flaten, J., and McIntosh, G., "Calibration of Temperature Sensors in Preparation for the 2017 Total Solar Eclipse," AHAC, Minnesota, 2017. Poster.

[21] Flaten, J., Smith, K., and Agrimson, E., “Applying Newton's Law of Cooling when the Environment Keeps Changing Temperature, Such as in Stratospheric Ballooning Missions," AHAC, Minnesota, 2016. (Under review.)

[22] Photos courtesy of Peace Sinyigaya. 